\title{
A Mole for Warm Magnetic and Optical Measurements of LHC Dipoles
}

\author{
L. Bottura, M. Buzio, G. Deferne, P. Legrand, A. Rijllart, P. Sievers \\ CERN, IATC Division, 121 I Genevi 23, Switzerland \\ H, Jansen, C. Gläckner, A. Köster \\ Fraumboter [rstitul, IPT, Aachen, Germany
}

\begin{abstract}
Alstract-A new rotating coil probe (a mole) has been developed for the simultaneoms measurement of the magnetic fied and magnetic axis of warm superconducting IHC dipoles and associated corrector windings, The mole houses a radial rotating coil and travels inside the magnet aperture hy means of an externally driven two-way traction belt. The coil is rotated by an on-board piezo notor, being tested in view of future devices for cold measurements as the only type of motor compatible with strong magnelic fields. A virtual light spot is generated in the coil ecnter by a I did source. The position of this light spot is measured from the outside by a system including a telescope, a CCO comen and a JSSP. Jigs on reference granite tables are used to transfer the optical measurements to the magnet fiducials. We describe here the main characteristics and performance of the mole.
\end{abstract}

\section{IN'TRODUCTION}

The measurement of the ficld quality of accelerator magnets is among the main ingredients in the construction of today's accelerators. With the advent of high lield superconducting magnets with long and narrow apertures, moasuring technologics have had to be adapled or newly developed. Pionecring efforts bad boen already invested since 1985 at BNI where the "mole" technology was first developed [1]-[2] and at DESY, where it has been further pursued for the test of HERA magnets [3].

A mole consists essentially of a slender container driven along the magnet aperture, carrying on board a rotating search coil with a motor to turn it and an angular oncoder to relate induced wolage to angular position. As for previous accelerator projects like the SSC [4], moles were also taken into consideration within the seenarios developed for the tests of LHC magnets [5]. Since, however, the bulk of magnet $1 \mathrm{csts}$ at $1.8 \mathrm{~K}$ will be made with "long coils" for the dipoles [6] and scanning machines for quadrupoles [7], moles will only be used for the series test at room temperature of dipoles and for special sample tests of dipoles at $1.8 \mathrm{~K}$. The ratler low magnetic field level (30 mT) used for room temperature testing of the LHC dipoles, in addition to the comfortable $50 \mathrm{~mm}$ aperture sizc, alteviate considerably the technotogical clallenges. This allows us to devise user friendly and reliable cquipment, essential for series warm moasurements of 1200 dipoles at the factories as well as at CERN. Nevertheless, we have selected most components in view of investigating then for the use in future moles for highfield tests of magnets al sunetfluid Helium temperatue $(1,8 \mathrm{~K})$.

As an additional feature, an optical system was added to track the lateral position of the mole during ils trip along the $14.2 \mathrm{~m}$

Rocived Septumber 27, 1999.

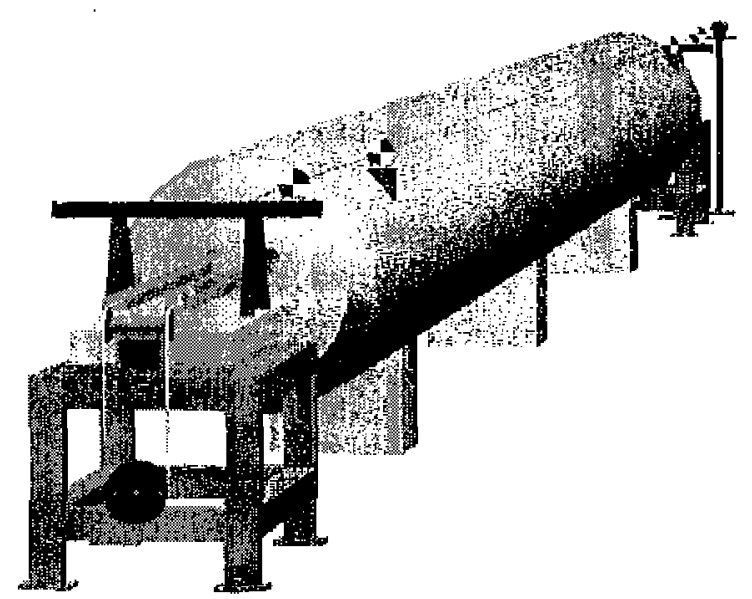

Fig. I. Schematic mole bench layout showing a dipole tunder test, the nole on the rear reference bench and the transpor systeril.

Iong and slightly bent aperture, with the goal to measure simultancously the ficld and the magnetic axis as well as the physical center of the aperture along the dipole.

The only "accelerator typical" component in the mole is the search coil, which was therefore dosigned by CERN [8]. All other components such ats motors, level meters, eneolers, motion controls etc. represent technologies which are available today in specialized industry conceroed with micon mechanics, sensorics, opties and roboties. Therefore, it was decided to develop this mole together with industry, lollowing a CERN performance specification.

This papel describes the design and commissioning of the mole and the expericnce gained using it for room tomperaturo measulements of LHC dipole prototypes.

\section{DESCRYPTION OFTHE SYSTEM}

An overall vicw of the mole test hench is shown in Fig. I, while Fig. 2 shows a schematic vicw of the mole assembly. The main component is the $\varnothing 41 \mathrm{~mm} \times 750 \mathrm{~mm}$ seatch coil (h), made of two glass-liher reinforced epoxy half shells enclosing three $11.5 \mathrm{~mm}$ wide radial coils. Each coil has 400 turns and an effective surface of approximately $3.4 \mathrm{~m}^{2}$. The coil surfaces, relevant for the measurement of the dipole strength, have been calibrated to $10^{-4}$ accuracy in a reference dipole [8]. The outermost radius of the two external (measurement) coils is $19.7 \mathrm{~m} n$. The central coil is used for dipole bucking. The coil is supported at either ond by high quality cerumic (SiN) ball bearings ( $f$ ) and is enclosed in a carbon fiber shell.

An optical system tracks the transverse position of the mole in the magnet cross section, so that the magnetic axis measured in 
the reference frame of the rotaling coil cal be transterred to external fiducials. A light cmitting diode (J.liD) mounted on the rolating axis of the front coil flange (i) is used to create a small light spot which is viewed from the front reference bench by at fixed, pre-aligned, high quality commercial straightness telescope. This telescope is fitted with a molurized locus, a CCD concra and a Digital Signal Processor (DSP) performing image treatment. Travelling in the bent aperture of a dipole the molc has a pilch and yaw up to 2 mrid. At such angles a teference mounted at the front of the coil has a substantial laterol eyror with respect to the coil center locatton. I'or this reason the light spot is viewed through a lens mounted in front of the LED, projecting a virtual image of the light spot into the center of the rotating coil.

In order to keep clear the line-of-sight for the optical tracking at the front of the coil, all other components had to be concentrated on the opposite side. These components include the holtow shaft optical angle cncoder (e), with 1024 counts per revolution, and a helical damping coupling (d), made of polyinide and supporting the lexihle signal cable spiral emerging from the coil. The signal cable is a bunde of 7 microcoaxial cables, frec to wind and unwind as the coil executes a cycle of three forward and backward rotations. Fach measurement is taken as the average of a complete forwand and backward coil revolution. In addition to this measurement turn, one complete revolution is used for the acceleration and deceleration of the coil.

An ultrasonic tratvelling-wave picro-motor (b) with a 3:1 plastic reduction gear (c) is mounled downstrenm of the helical coupling. Such motors appeared only tecently on the market, and are particularly suitcd for our application as they have compact size (approx, $\varnothing 30 \mathrm{~mm} \times 20 \mathrm{~mm}$ ), intrinsic slow rotation $(2 \mathrm{~Hz}$ ) and the capalility to work in strong magnetic fields. Sudies are still in progress to improve the control of the velocity which by now is constant within $\pm 8 \%$, marginally adequate for magnetic measurements. If necssary the piczomotor could be replaced by a standard DC motor-roductor unil for low licld measurements. We have made use of the through axis in the motor to install downstream an auxiliary potentiometer (a), necessilry for the control and limitation of the rotation.

Each block of components in the mole is contained in a separate non-magnetic stainless sted bousing. The housings are mechanically fitted to wach other alter interconnecting the electrical cables. This assembly forms an autonomous drive unit. The coil is mounted on the drive unit and inserted therealiter into a high strength carbon fiber tube that completes the assembly of the mole into a monolithic container. The support in the magnet aperture is provicted at either end by triple rolles that perrit at stnooth longitulinal movement (see Fig. 3). One of the three rollers in eacl unit is spring loated in order to atcommodate the \pm 0.4 nun toletance along the magnet apertere pipe. A triple roller unit lorms part of a ring sliding around the mole container, allowing relative rotation between these two components. 'This mechanism is necessary to orient the mole into a proper working posibion. Travelling in the magnet the mole changes its orientution by up lo a lew degrees per meler of travel, depending on the mechanical precision of the rollers and the gitiality of the inner surface of the magnet aperture. This rotation must be corrected, to avoid twisting of the traction belt and of the signal cable and to get as close as possible to the zero of the mole level meter where the accuracy of the reading is the highest.

The correction of the orientation is done by means of an active on-board auto-leveling system, consisting of a coarse ( $11^{\circ}$ ) and a finc $\left( \pm 2.5^{\circ}\right)$ level meter piloting a motor. The motor engages via a pinion system into the rear triple roller support, thus changing the ortentation of the mole unit relative to this roller support. Since Iriction blocks the latter against arimuthal rotation in the aperture pipe of the magnet, it is actuatly the mole which orients itself into the desired position. The conse level meter is used to level the mole to within a few Jrrad. The line level measures the linal orientation with a precision of \pm 0.02 mrad. A reference surface on the outside of the mole container can he used to verify on the reference benches the orientation of the mole angainst the leve] meters.

The molorired drive mechanism lon fongitudinal displacement and positioning of the mole is shown in Fig. 4, together with one of the two granite tables placed at either end of the test bench and used to establish the necessary reference positions. The supporls installed on cach table, made of two half" shells, seve primarily for ease of instalialjon and to "park" the mole outside of the magnet. They have the same inner diameter as the magnet aperture, thus ensuring smooth movements into and out of the magnet. The supports are duplicated for each aperture of the magnet, and the mole bas to be moved manualy from one aperture to the other.

A non-magnelic Inconcl transport tape is athehed at either end of the mole (sec cletail in Fig. 3). The tape lorrins a loop closed through the other magnel aperture. A pre-tension of about $150 \mathrm{~N}$ is applied to ensture precise and reproducible axial positioning. The longituclinal position is monitored continuously viat an cxternal angular eneoder, driven by the transport tape, and is checked at refertence positions at the end of each trip. These references are materialized by jight reflection detectors on the half shells. The longitudinal position has a reproducibility better than $0.2 \mathrm{~mm}$ at the references, while the overall precision of the
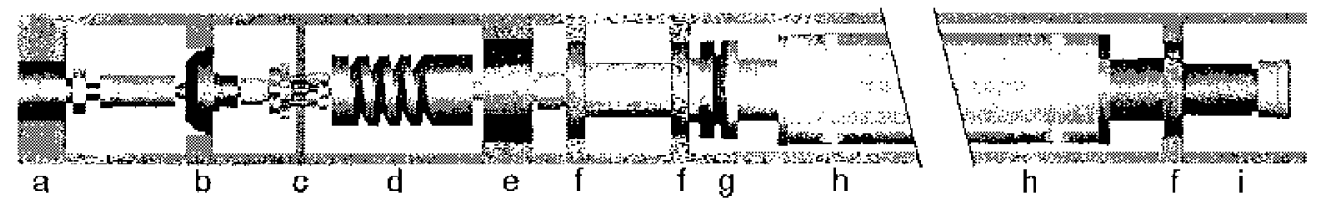

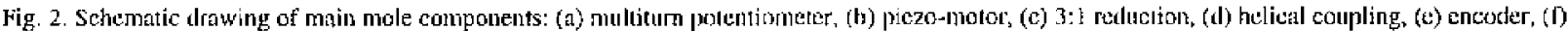
cernmic ball benting, (g) Ti conpling, (h) coil, (i) LED nud optics. See lext for a detailted description. 
Iongitudinat positioning over the whole magnet lengh, important lor integral ficid measurement, is better than $0.5 \mathrm{~mm}$, i.c. less than $10^{-4}$.

One single multi-wire signal cable collecting all clectrical connections, energes at the rear of the mole (see Fig. 3) and is pulled logether with it back and forth along the magnel. The cxeess of cable is stored via a motorizer drive in a containcr placed in front of the rear benct (see Fig. 4).

'The reference benches, at the two mingnet conds, provide the mean to transfer the optical mensurements inside the magnet to the outsicle tiducials of the magnet. This is clone in subsequent steps. In the first step the telescope-CCD unit is used to meastre the position of the light-spot with the mole placed into procise and reproducible reference supports on the gratsite base of ench reference bench. 'The transfer from the gongite base to auxilaty fiducials, in line of sight with the outside magnet fiducials, is established by themmally stable jigs, made of carbon reinforced structures, firmly mounted onto the granite basc and carefully surveycd. The auxiliary fiducials are finally related to the outside magnet fiducials by standard surveying teclnniques.

\section{III, System PerformanchS}

\section{A. Field Measurements}

The main task to be accomplished by the mole is the measurement of the ahsolute value and ditection of the dipole field, as well as the higher order multipoles atong both apertures of a magnet. These are obtained applying standard toelmiques for search coiss. The field integral in the magnet, relevant for the necelerator performance, is obtained scanning the whole aperture in steps equal to the coil lengh. As an example we show in Fig. 5 results of the measurements of the 10-m long prototype dipole MBL1N1. We have reported there the measured dipole field, its clitection and the modulus of the higher order barmonics relative to the dipole lield and senled by a factor $10^{4}$ (i.e. in units). The compensation of the main dipole component necessary for an aceurate moasurement of the harmonics is: performed analogically, subtracting the signal of the central coil from the roading of the measutement coil. The compensation ratio oblained is about 2000 , averaged between forward and backward rotation. We have achicved a measurencht

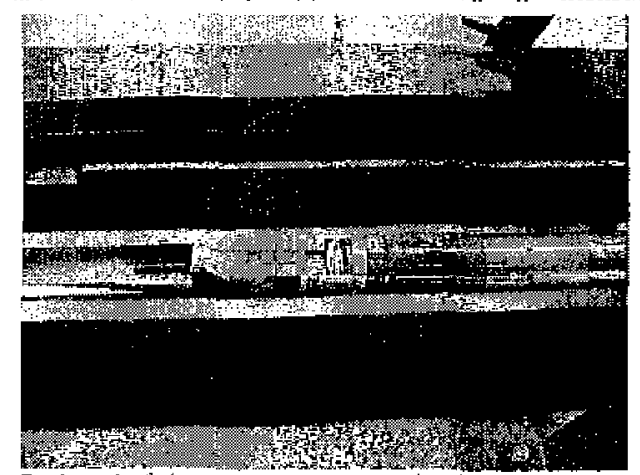

Fis, 3. Back end of the note showing the signal and control calble, the connector and a triple rotler mail. reprolucibility of the order of $2 \cdot 10^{\text {th }}$ relative to the main dipole component up to order 15.

The measured dipole direction is shown in delail in Fig. 6, and compared to independent measurements taken using diftorent equipuent [7]. The angle is corrected atter the meastuenont for the local residuai vertical tilt of the mole and for the systematic oflset between the on-board level-meter and the cnooder "zoro" pulse. The laticr is a constant that we have obtained from a calibration measurement in a relerence dipole with a well-known fick direction, observing the phase of the main harrononic relative to the orientation of the mole. The estimated precision of the angle measurement is about $0.2 \mathrm{mrad}$.

The location of the anagnelie axis relative to the rotation ax is of the search coil is computed from the measured harmonics. For the LHC dipoles we have found that a gool working definition of the magnetic axis is given by the location in the magnet cross section where the non-allowed multipole of ordes 10 vanishes. This corresponds to the assumption lint the component of order 10 is cotitely caused by lecd down from the higher order harmonics. In fact the LIIC dipoles have a strong intrinsic geomelric multipole of order 11 , thus justifying the assumption. The coil rotation axis is measired optically and transferted to the magnet fiducial reference frame (sce next section). It this way, all parameters relevalut for the mensurenent of the magnetic fields in the IHC dipoles are achicved simulancously by a single passige of the mole, which is vilat for the efficient and speedy acceptance procedure of magnels during series production. A single, local magnetie measurement takes in fact only a few scoonds. At present every measurement is repeated at Jenst 10 times, in order to build un statistical confidence. The scan of both apertures of a whole rnagnet can be accornplislicd in about one hour',

\section{B. Optical Measurwintents}

The transverse position of the light spot is obtained calculating the eenter of gravity of the image on the CCD. A given number of takes (typically 30 ) are averaged to reduce the influence of ail turbulence. A prelonded soltware calibration

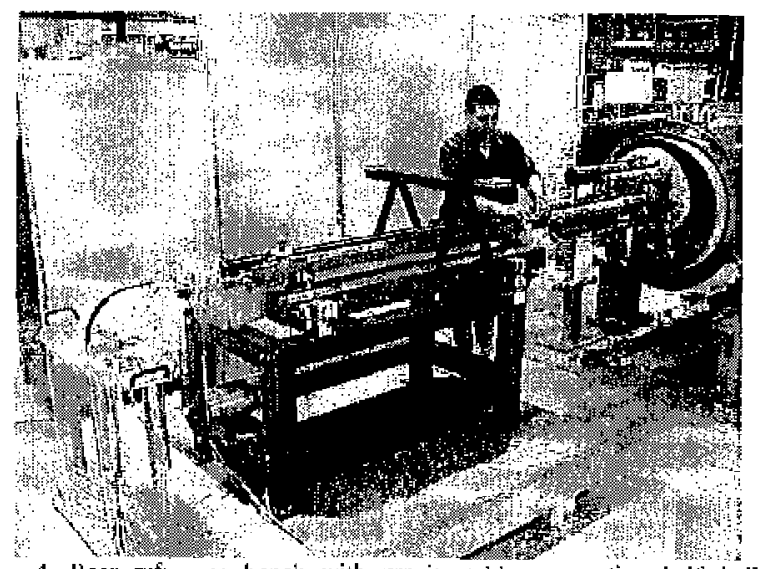

Fig. 4. Rear reference bench with granite table, supporting hall-shells, reference jig. l'ansport systern and cable container. 
map is used to compensate for longiludinal distance eflects. 'The moasuring range of this system is \pm 2 17m vertically and $\pm 7 \mathrm{mmm}$ horizontaily (as sequired to cover the 9 mm sagitla of a curved, 15-m long dipole magnet aperture). 'The procision after colfibration is better than $60 \mu \mathrm{m}$ oves a $20 \mathrm{~m}$ range, well exceeding specifications $(100 \mu \mathrm{m})$.

In Fig. 7 we show an example of the measured trajectory of the coil center in the aperture of the MBLINi dipole. The mole follows the curved aperture pipe, with a sagitla in $x$ (horizontal) dircetion of approximately $8 \mathrm{~mm}$. Our results are compared to an independent measurement taken with a combined lasedPSD system [9]. The average diflerence between the two measurements is $74 \mu \mathrm{m}$. It should be noted that geometrical crrors of a low fom in the optical unit assembly can lead to a transverse displacement of the virtual spot of a few temths of mm, due to the magnifying effect of the lens. This las been observed and corrected laking the

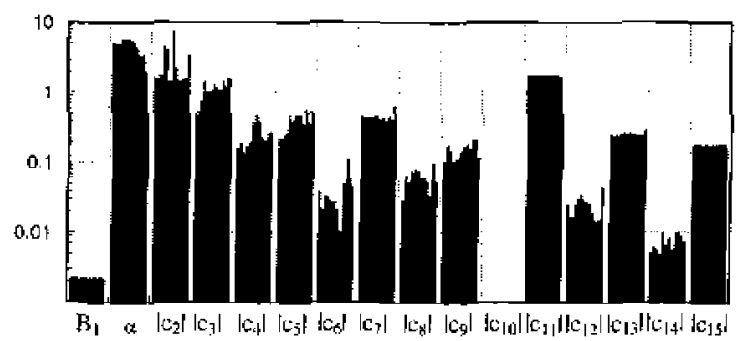

Fig. 5. ['sold menturement in MRLINI prototype slipole, cach bar representing a different longitudinal position $\left(B_{1}\right.$ is in $\tau$, the angle $x$ is in mial, the hatuonies ate in units (0) $17 \mathrm{~mm}$ ).

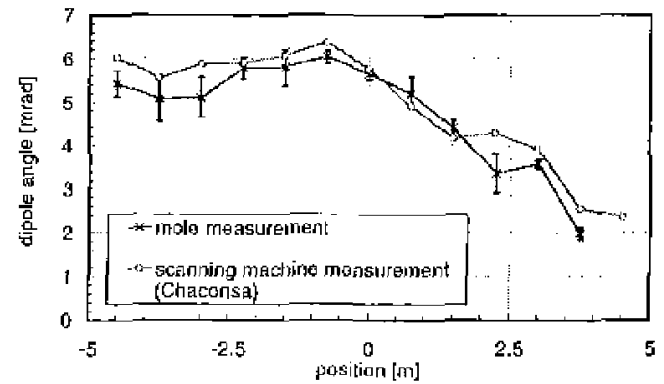

Hig. 6. Comparison of measused ligeld angle with the nole and with an atsonated scanning mohine [7] in like MBI,IN] LHC prototype dipole.

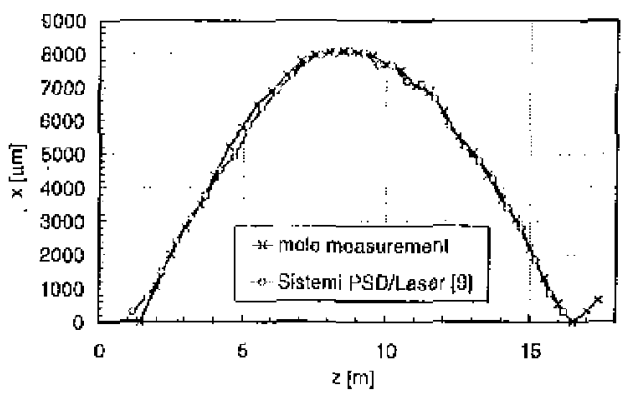

rig. 7. Fxample of optichl mensurement: besm pipe curvature in the nisplane of the MBLINI dipole prototype, compared to results from [9]. a verage of two measurements al coil orientations $180^{\circ}$ apart.

The Joule power healing the magnel during magnesic meastrements can impair severely this excellent perfornunce. Thermal gradients in the aperture deviate the optical pellh up to a lew tenths of a mm. Several solutions are being considered, including a small controlled gas flow along the magnet's aperture pipe, naking optical measuremerat runs before powering the manget and, most promisingly, the adoption of a very low power quadrupole conliguration in the dipole for magnetic axis measurement.

\section{CONCLUSTONS AND OUTLOOK}

Our initial experience with the mole shows that this probe is able to carry out magnetic and geometrical measurenents with a precision egual to or exceding the specifications. Reliability and user-triendlincss, so far, appear to be compatible with the severe demands of the serics LHC dipoles test compaign.

Much of the mole's complexity stems from the requirement to measure the magnetic axis relative to the magnet fiducials. In fact, if the goal were simply to measure the axis position relative to the cold bore, the system of reference jigs and surfaces, as well as the auxiliary system to measure their aligmment with respect to the magnet fidtucials could be dropped. Moreover, were the axis not required at all, the optical measuremest components could be climinated altogether and both the trausport mechanism and the internal layout could be simplifjed.

The next major target now is to supply a mole for measurements of dipoles (and, possibly, of LHC quadrupoles) at liquid helium temperature, one of which has already been ordered. This probe represents a more difficult challenge as it must work, anong other things, uuder vacuum (to avoid thermal gradient effects on the optical path) and within a more resitricted volume ( $40 \mathrm{Inm}$ anticyostal). Fhis mole will only be used for spot checks including the detection of the magnetic axis at high ficld.

\section{REFFRENCES}

[1] H. llemen, G. Gantis, R. llogue, E kogers, P. Wandener, E. Willot, "Measirement of the migneric tield coefficiems of particle acolcmitor imagnts', PAC 89, Chicigo, IL, USA.

(2] E. Willen, P. Dahl afd J. Herera, "Supenonducting matats", SLAC Surumer Sction 1985, Ail Conf. Proc. 153, Vot. 2.

[3] $\mathbf{R}$ Meinkt, "Methods for prokluction measurenuents of supereonducting matnets", Intotnal Report DESY HER A 90-06, A pii] I990.

[4] R. Thomas ot al., "Performance of lield masuritig probes for SSC matgnets," pp. 715-7I8, Supercollider 5, ed. P. Hale, Plemwn Pres, Now York, 1994.

[5] L. Walckiers ef aL. "Towards series meastrements of the I.HC superconducting dipole nagnets", Proce of 1997 Part. Acc. Cont, Vancouver, p]). 3377-3379, 1997.

[6] J. Billan, L. Botura ot al "Twin rotating coils for coid musnetic mensunements of $15 \mathrm{n}$ long LHC dipoles", $16^{\text {dis }}$ Intemational Conference on Magnet Technology (MT 16) Ponte Vedra Bench, IL., USA, 26 Sept - 2 Oat., 1999.

(7) J. Bilian, J. Buckley, R, Salyan, I'. Sievers, L. Walckiess, "Thesign and test of the henches for the magnetic incisurement of the LHIC dipoles", ILEL Trans. Mcig. vol. $30, p_{13}, 2658-2661,1994$.

[8] J. Billan, CERN, Gencwa, Swiper]and, private communication, 1998

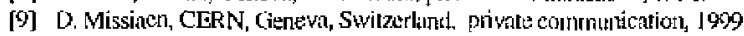

